\title{
QUANTITATIVE PARAMETERS OF PORE TYPES IN CARBONATE ROCKS
}

\author{
Dayse Daltro de Castro and Paula Lucia Ferrucio da Rocha
}

\begin{abstract}
Carbonate rocks are controlled by variable depositional systems and diagenetic process and have a wide variety of pore and grain shapes/sizes. Those characteristics imprint different petrophysical properties in carbonates, which are more difficult to predict than in siliciclastic rocks. Measurements on carbonates reveal that pore/rock type parameters are function of total porosity and play an important role in the relationship between porosity and P-wave velocity. In this research, the database consists of carbonate rock samples with a wide range of bulk porosities, pore types and rock textures, from different Brazilian areas in Southeast Continental Margin. We investigated the hypothesis that scatter values observed in velocity at a given porosity can be explained by pore types and pore shape characteristics. The quantification of pore shape/size distribution in each sample was based on four geometrical parameters from thin sections measurements - pore size, aspect-ratio, tortuosity and pore complexity. By multivariate analysis, those parameters were applied in the correlation between porosity and P-wave velocities in order to reduce scatter values normally observed.
\end{abstract}

Keywords: petrophysical properties, thin sections, porosity, P-wave velocities.

RESUMO. As rochas carbonáticas são compostas por calcários e dolomitos de diversos tipos. Além da deposição, os processos de cimentação, dissolução e recristalização transformam essas rochas, produzindo uma grande variedade de tamanhos de grãos, formas e estruturas de poros, criando ou reduzindo porosidade e permeabilidade. Estas características dos carbonatos imprimem grande peculiaridade às propriedades físicas tornando-as mais difíceis de predizer do que em rochas siliciclásticas. As formas dos poros também afetam as propriedades físicas das rochas carbonáticas, produzindo um efeito específico nas propriedades acústicas devido às relações geométricas com a fase sólida das rochas. Por tudo que foi exposto, a compreensão do sistema de poros leva ao melhor entendimento e quantificação das propriedades petrofísicas das rochas carbonáticas. Nesta pesquisa foram utilizadas rochas carbonáticas com diferentes texturas, porosidades e tipos de poros de diferentes áreas da Margem Continental Sudeste Brasileira e o principal objetivo foi melhorar a correlação entre a porosidade e a velocidade das ondas P obtidas de plugues de rochas secas e úmidas. Para tal, foi realizada a avaliação e a quantificação do sistema poroso utilizando a análise multivariada de parâmetros geométricos (tamanho, forma, tortuosidade e complexidade do poro) obtidos de fotografias digitais de lâminas delgadas, para auxiliar na redução da dispersão normalmente observada nas relações entre velocidade e porosidade.

Palavras-chave: propriedades petrofísicas, lâminas delgadas, porosidade, velocidade das ondas P. 


\section{INTRODUCTION}

Carbonate rocks are composed of various types of limestone and dolomites widely distributed from the Precambrian to the Recent. An important aspect of these rocks is their dependence on organic activity and high susceptibility to post-depositional processes such as dissolution, cementation, recrystallization and replacement. Cementation and dissolution processes promote carbonate transformation that results in a large variety of grain sizes, pore shapes and structures, creating or reducing porosity and permeability.

Pore shape also affects the physical properties of both siliciclastic and carbonate rocks, producing a specific effect on the acoustic properties due to geometrical relations with the rock solid phase (Rafavich et al., 1984; Ehrlich et al., 1984, 1991b; Vernik \& Nur, 1992; Lucia, 1995; Anselmetti et al., 1998; Anselmetti \& Eberli, 1999). For example, elongated pores have different effects on these properties compared to rounded pores produced by moldic dissolution. Consequently, all these factors lead to large variations of rock physical properties making their detailed and rigorous study important.

Researches were conducted over time to classify pore structure using the digital images of thin sections for quantitative analysis. These images in different scales are obtained using a range of microscopes from optical (OM) to scanning electron microscope (SEM). Lucia (1995) study was based on the grain size and whether the vugs were touching or not. Anselmeti et al. (1998) quantified the pore shape in carbonates from digital images obtained by OM and SEM. The authors determined Gamma parameter (ratio between pore perimeter and area) by using thin sections and correlated it with permeability measurements. They reported difficulties in correlating the geometrical parameters with the classical porosity types. Anselmeti \& Eberli (1999) estimated pore types from sonic profiles of both density and porosity. This type of analysis works well when adjusted to the laboratory measurements.

Baechle et al. (2004) used digital analysis technique to measure pore shape in thin sections. Han (2004) used in addition to petrographic analysis in thin sections (SEM), image analysis for this classification. The author defined that the contact between grains was an important aspect of the porosity and determined six types of pores as follows: intergranular, intrabioclastic, intracristaline, vuggy, micropores in limestone muds and fractures.

Weger (2006) quantified pore geometry and determined which parameter would best characterize pore space using the images of thin sections acquired with plane and crosspolarized light.
Taking into account the number of studies already performed and the importance of understanding the geometry of the pore space, this study aimed to evaluate which pore characteristic, obtained from digital photographs of thin sections, best explain the dispersion observed in the velocity versus porosity diagram. Reducing this dispersion allows a better quantification and correlation of these physical properties in carbonate rocks in cases of absence of one or other information. These properties are very important in the petroleum industry, particularly to conduct 3D geological models. Thus, greater accuracy of physical parameters allows establishing more efficient predictive geological models.

\section{PORE CHARACTERIZATION USING DIGITAL IMAGE ANALYSIS}

This study focused on quantifying the size, shape and distribution of grains and matrix of carbonate rocks using digital images of thin sections in order to determine macro and micro porosity and its correlations with other physical parameters.

The method is well established since the 1990s and has been used by some authors, Ehrlich et al. (1984, 1991), McCreesh et al. (1991), Gerard et al. (1992), Anselmetti et al. (1998) and Weger (2006).

We used 71 (seventy one) thin sections of plugs with a wide distribution of rock types and pores. The samples consisted predominantly of calcium carbonate, but some dolomite samples were also analyzed. Textures of the thin sections were classified according to Dunham (1962) while pore types according to Choquete \& Pray (1970).

The method used (DIA - digital image analysis) was developed by Weger (2006) and allows a 2D description (thin section) of pore size, roughness, ratio and complexity. The DIA analysis was performed using MATLAB ${ }^{\circledR}$ (Matrix Laboratory) software that uses mathematical simulation to perform matrix operations and, among others, assists in signal processing. Subsequently, the parameters were analyzed with the laboratory measurements of porosity and velocity of $\mathrm{P}$-waves to obtain more reliable relationships between these parameters.

\section{METHODOLOGY}

The DIA (digital image analysis) method comprises of three steps: image acquisition, segmentation and calculation of pore shape parameters. The segmentation process is the separation of a specific feature from the background and it was performed on colored digital images acquired in standard RGB (red-greenblue) which were converted to a binary BW (black and white) format to identify, respectively, the pore and the matrix/cement. 
In this study, the object feature of segmentation was the rock pore that was quantified and its geometry parameterized.

The steps of the DIA method are described below.

\section{Acquisition}

In the first step, the thin sections were photographed under plane and cross-polarized light (XPL) at different angles $\left(0^{\circ}, 20^{\circ}\right.$ and $40^{\circ}$ ). The use of cross-polarized light at different angles facilitates the segmentation of the pore space of the matrix/cement (Fig. 1).

The epoxy resin does not fully impregnate some types of rocks and produces air bubbles that due to the white color can be wrongly classified as a mineral, also white (Figs. 1 and 2). The cross-polarized light at different angles also enables to confirm whether it is a mineral since the colors change (extinction) according to the crossed nicol angle. The pore space impregnated with epoxy is always isotropic, that is, it remains extinct under the cross-polarized light at any angle. The redundancy of the crosspolarized light allowed greater accuracy in the segmentation of the pore space of the matrix/cement, identifying and computing as pore, portions of the thin section that had air bubbles.

Each section was divided into four quadrants that were photographed with overlap of about $30 \%$, taking care to set the parameters of focal length and aperture of the photographic cam- era to obtain photos with the same quality. Seventeen images were acquired for each thin section following the order: one image with plane polarized light (PPL) (Fig. 1(a)) and three images with cross-polarized light (XPL) at $0^{\circ}, 20^{\circ}$ and $40^{\circ}$ angles (Fig. 1(c)-(e)). After obtaining the four images in the first quadrant, the section was moved to the next quadrant, where the same procedure was repeated. Subsequently, a scale was also photographed.

\section{Photo processing}

Photo processing for further segmentation started after all seventy one sections were photographed totaling 1,207 photos.

The MATLAB ${ }^{\circledR}$ software was used to assemble the pictures of the four quadrants into a photo mosaic, which resulted in four photos of the whole section as follows: one with PPL (Fig. 1(a)) and three with XPL at $0^{\circ}, 20^{\circ}$ and $40^{\circ}$ angles (Figs. 1(c), (d), and (e)). The absolute difference in the intensity of XPL pictures was calculated as the average pixel by pixel that resulted in the final image shown in Figure 1 (b). The XPL intensity variations at different angles show the presence of either isotropic or anisotropic minerals or resin. The great variations show the presence of anisotropic minerals while small variations indicate the presence of isotropic minerals or resin.

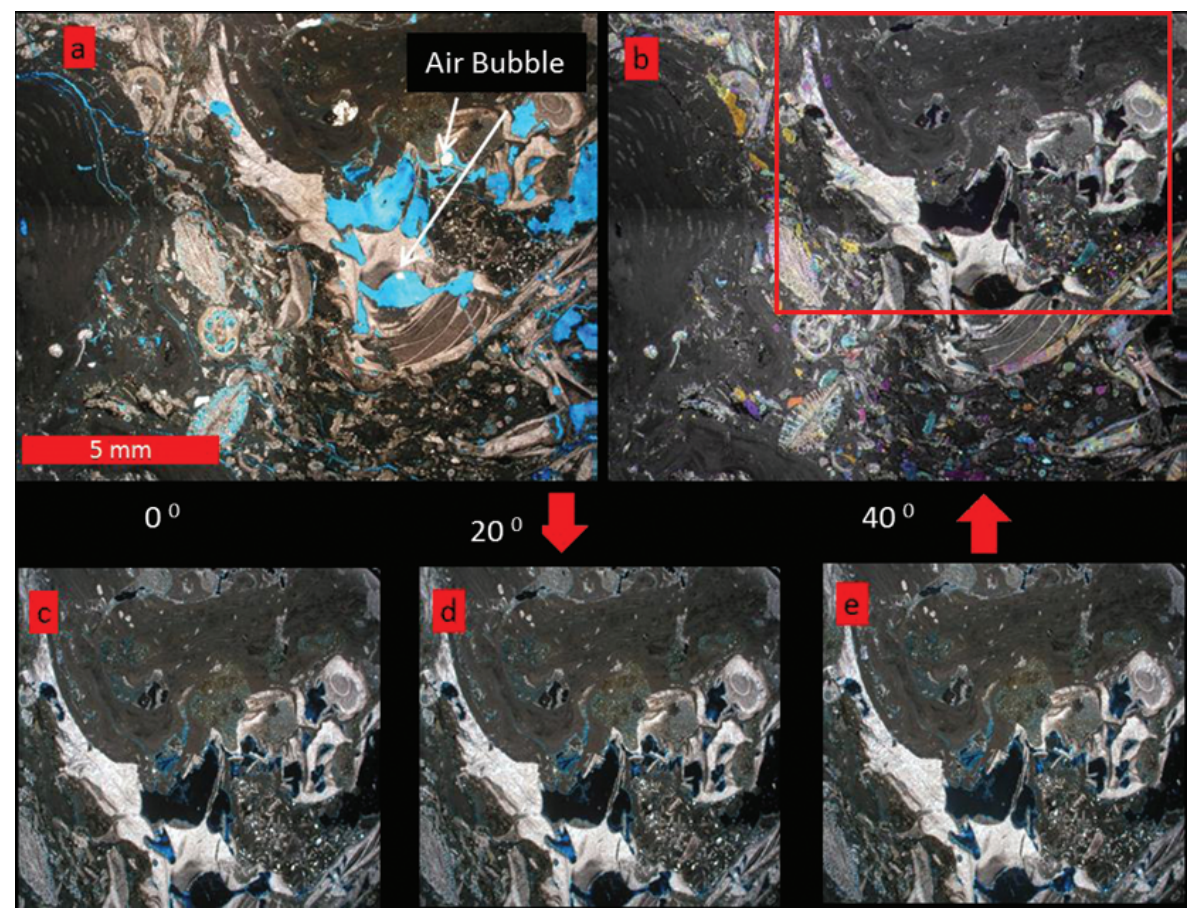

Figure 1 - Process to determine the absolute variation of XPL in digital images of thin sections. (a) Image acquired with plane polarized light (PPL), where some pores were not perfectly impregnated with blue epoxy resin; (c) to (e) images acquired with XPL at different angles. The attribute of XPL variation was calculated as the absolute mean of the light intensity variation obtained in the images from (c) to (e), and it is represented by image (b). In (b) the pore space is colored black. 


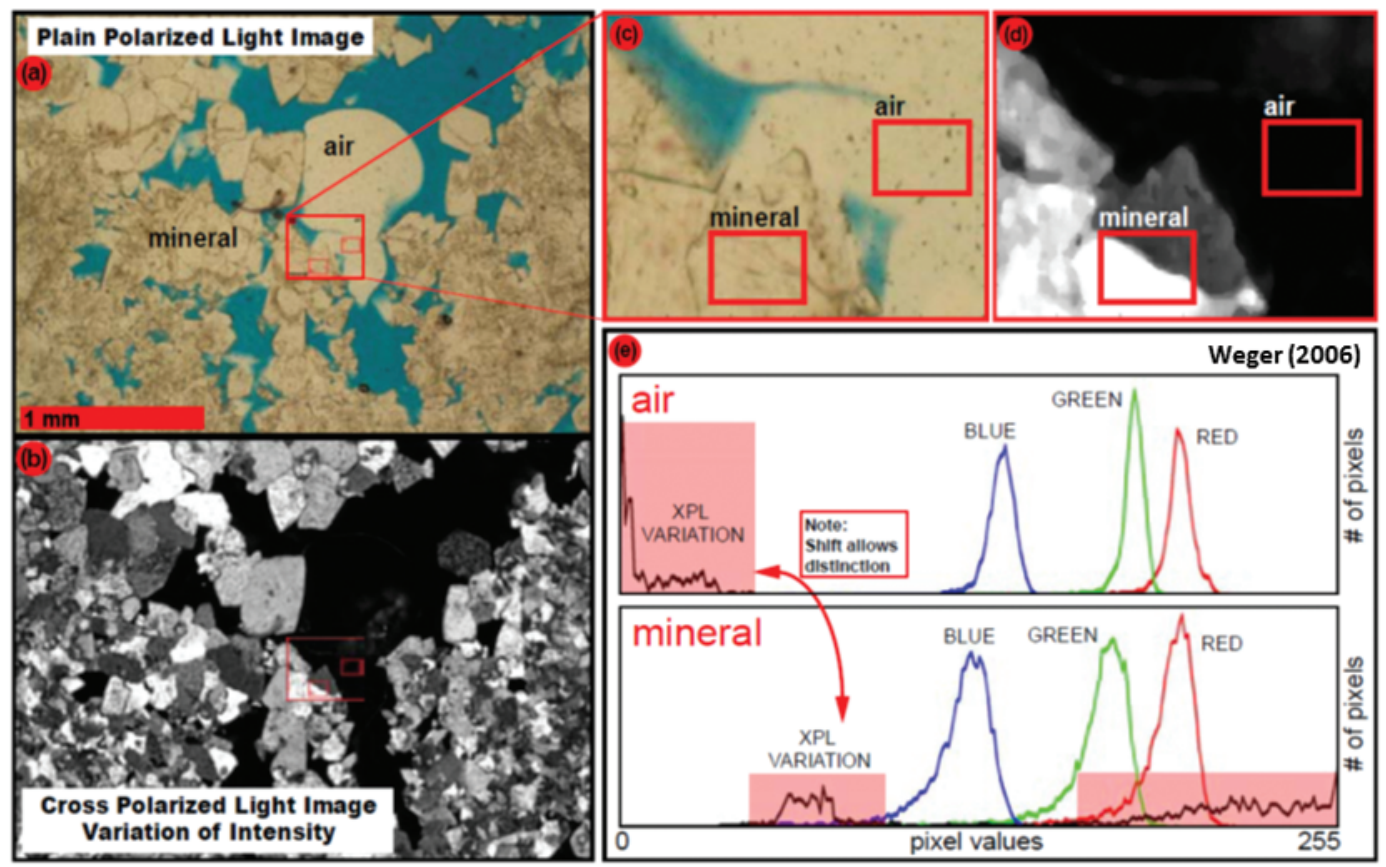

Figure 2 - (a) photograph of a thin section of carbonate rock sample impregnated with blue epoxy resin, with PPL. Minerals and grains are colored beige. (b) photograph of the same thin section using XPL at different angles obtained from processing three images, called absolute variation photo. The pore space is blue except in the portions with air bubbles, which have the same color of the mineral in the rock matrix. (c) and (d) show details, in (d) the photo of absolute variation of XPL shows the air bubbles of the minerals. In (e), it is noted that the RGB color palette alone does not discriminate the mineral air bubble; however, the XPL variation can separate them.

The final product for each section used in the next step was the following: a picture with PPL (Fig. 2(a)), a picture with XPL at $0^{\circ}$ angle and a picture of the absolute XPL differences (Fig. 2(b)). As seen in Figure 2(e), the PPL images acquired in RBG standard do not allow separating the mineral and air bubble areas; however, the XPL variations enabled this distinction since the values of XPL air bubbles are much lower than those of the mineral.

\section{Segmentation}

The method for classification and segmentation of the matrix/cement pore space is called hue saturation value (HSV)/XPL and consists of three steps. Firstly, in the cutoff selection tool (Fig. 3(a)), in the BLUE PICK parameters, the area covered by blue resin was identified by painting it red in the PPL picture (Fig. 3(b)). Secondly, the porous space left, which was not filled by epoxy resin (air bubbles), was identified adding saturation values in the parameters called XPL PICK (Fig. 3(a)). Therefore, the regions with low saturation, high intensity and low XPL variation that correspond to the pore space observed in each section were defined. After porosity was mapped, the image was processed to generate the BW image (binary image - black/white) (Fig. 4).
It is important to note that the porosity mapping process was based on photo observation to choose manually the parameters that best defined the pore space.

\section{Parameter calculation}

After BW images were generated for all thin sections, we ran the Particle Analysis software whose output was a list of all parameters determined for pore shape of each thin section.

The parameters for pore shape determined in this study were defined by Russ (1998). Russ described two types of parameters, global and local. The global parameters describe the whole section while the local parameters are obtained for each pore. From these, the basic parameters are measured directly while the calculated parameters derive from a combination of basic parameters and are calculated. The basic local parameters are area, perimeter and major and minor axis of the pore. Among the ones derived from local parameters, there are the equivalent diameter, the ratio between major and minor axis, circularity, roundness and compression. The global parameters are obtained from the local ones from the frequency distribution of these parameters. Thus, the local parameters are statistically distributed, defining the parameters that represent globally the pores of the referred section. 


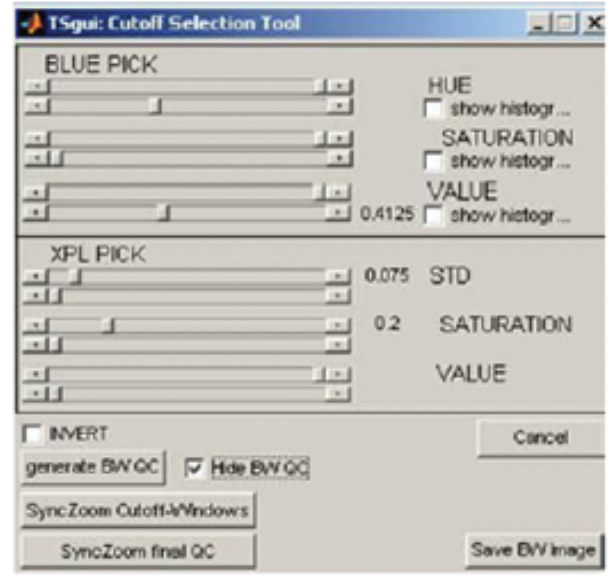

(a)

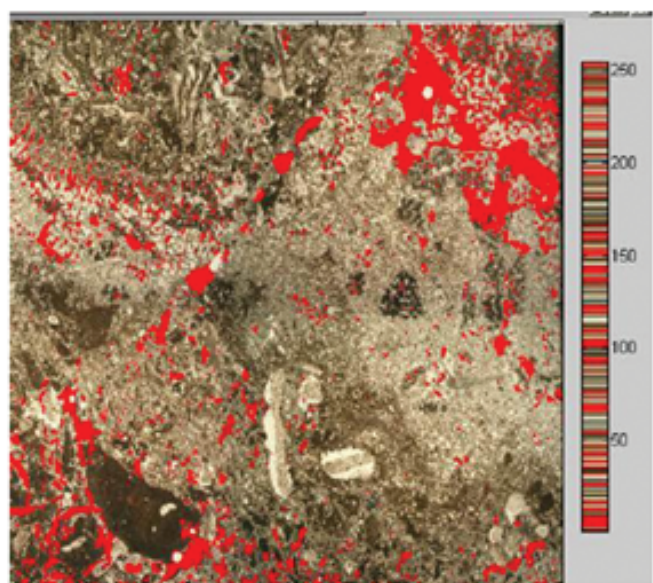

(b)

Figure 3 - (a) cutoff selection tool used to map the porosity of the thin sections; with the BLUE PICK parameter, the area with blue resin (pores) of the thin section was colored red; with the XPL PICK parameter regions with air bubbles not filled with blue resin were identified; (b) example of a thin section image where all mapped porosity was colored red.

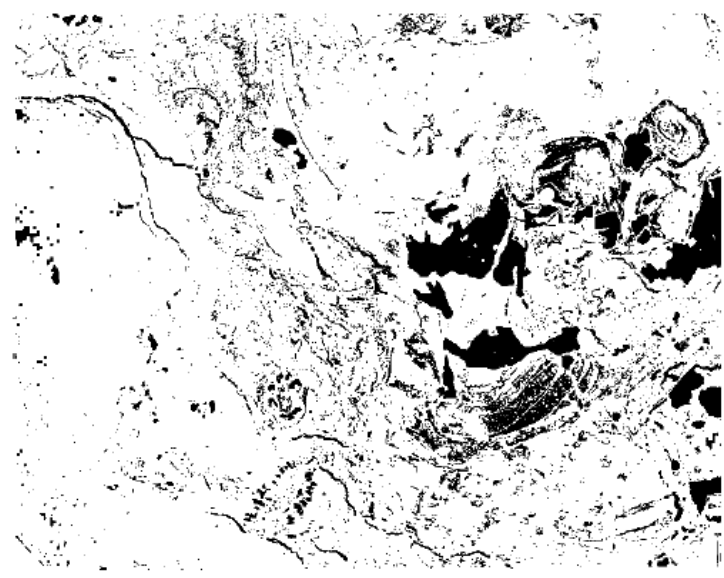

Figure 4-Example of the final image (BW - black-white) of the thin sections shown in Figure 1 with mapped porosity colored black.

Besides the 22 parameters defined in the DIA (digital image analysis) to quantify the pore space, many other can be obtained. The most important is to establish which ones best characterize and represent the dispersion observed in the diagram of linear correlation between velocity and porosity. From all the analyzed geometrical parameters, the ones with greater variation were Gamma, DOM (dominant size), perimeter over area (PoA) and the axis ratio (AR). Given the large variability observed, these parameters were chosen as the ones that best represent the different types of pores in the thin sections studied, and the elements responsible for the dispersion observed in the velocity and porosity correlation, as well.

\section{PORE SPACE}

Pore space is defined by the shape, size and geometry of the grain and rock matrix. The pore size is represented by the equivalent diameter, which is the diameter of the circle with the same area of the pore. The values that define pore size need to be normalized because rock pores have complex shapes that are difficult to be compared. After normalization, pore size is analyzed statistically and represented by the histograms seen in Figure 5 , where $x$ axis represents the classes of equivalent pore size and $y$ axis represents the frequency of pore size in relation to the total pore space. The red curve defines the cumulative area and was used to identify which pore size, besides being dominant, represents 


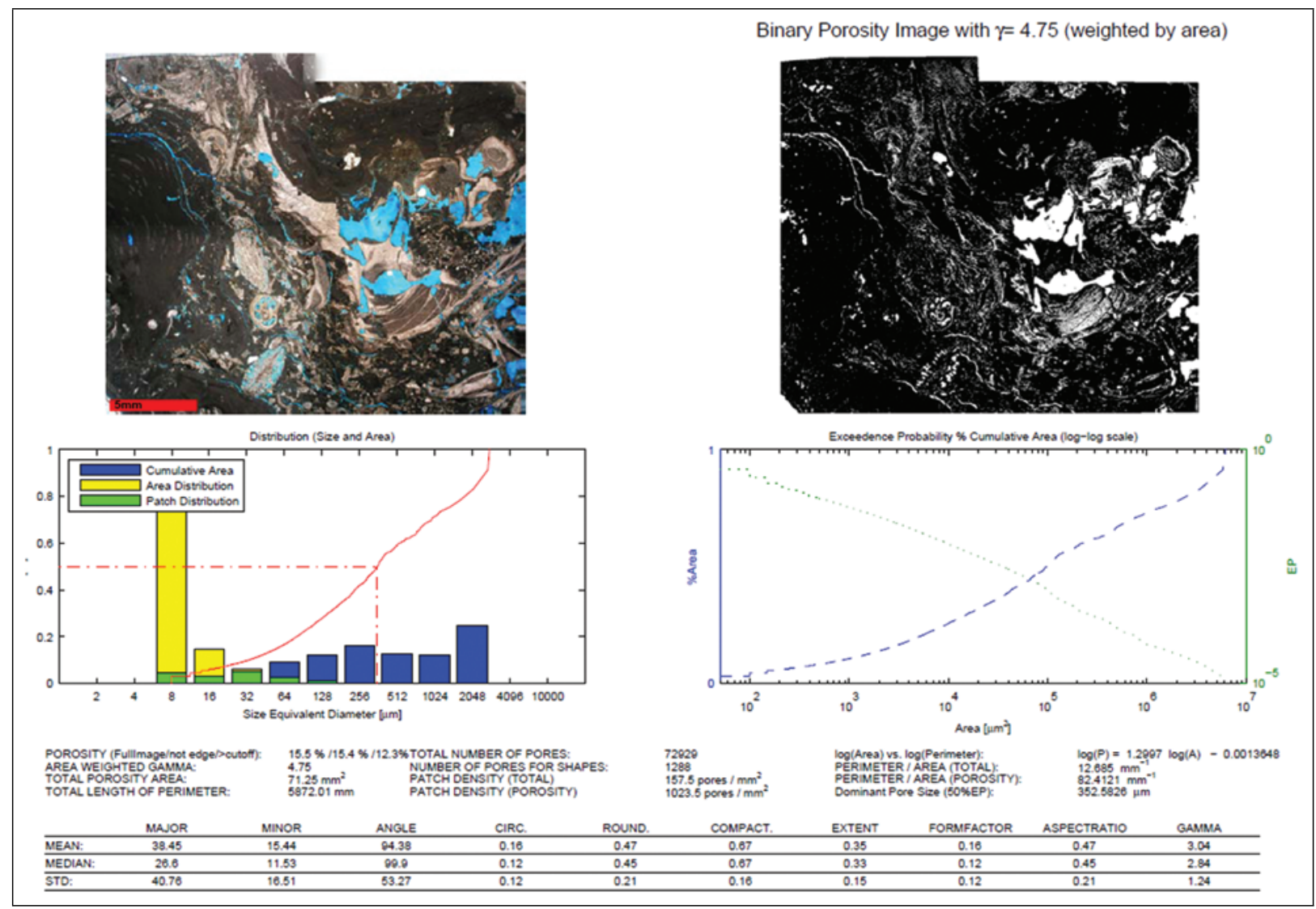

Figure $\mathbf{5}$ - Example of the statistical summary generated for the thin section shown in Figure 1. The statistical summary of each thin section shows a PPL image and another one binarized (black and white) with pores in white and DOM distribution.

$50 \%$ of pore space. DOM (dominant size) is an important parameter when analyzing the porous system and is defined by the pore sizes that occupy the first $50 \%$ of the area of the pore space. Large pores occupy half of the porosity observed in the thin section, but quantitatively are fewer. This parameter is important to identify microporosity.

The roundness of the pore has been used by some authors to establish correlations between the elastic parameters (Rafavich et al., 1984, Vernik \& Nur, 1992); however, Saleh \& Castagna (2004) used it to improve the estimate of the velocity - porosity relation. As the parameter is used to determine pore flatness, it is similar and correlates well with the axis ratio parameter $(\mathbf{A R})$, which is the ratio between the major and minor axis of an ellipse surrounded by the pore. It distinguishes elongated from star-shaped or circular features, but it is ambiguous to separate the circular from the star-shaped.

The Gamma parameter is the ratio between pore perimeter and area, and describes how circular is the pore shape. Gamma distinguishes elongated and star-shaped pore from a circular one, but it is ambiguous to separate elongated from star-shaped pores.

The parameter PoA defines the ratio between total pore perimeter and area. It describes how complex is the porous system independent of total porosity.

As seen in Figure 5, the statistical summary for each thin section studied presents a PPL image and another binarized (black and white) with the pores in white and the distributions of dominant pore size (DOM).

\section{RESULTS}

Figures 6 to 9 show the diagrams of porosity versus dry P-wave velocities obtained from plugs of carbonate rocks colored according to the values of Gamma, AR, DOM and PoA given by DIA performed in the thin section of the referred plugs. It is noteworthy that a constant factor was applied for the P-wave velocity that did not affect the analysis of the results.

The results show that Gamma varied between 1.5 and 6 . This parameter is very sensitive to pore tortuosity and complexity; however, by itself is not efficient separator of carbonate rock/pore 


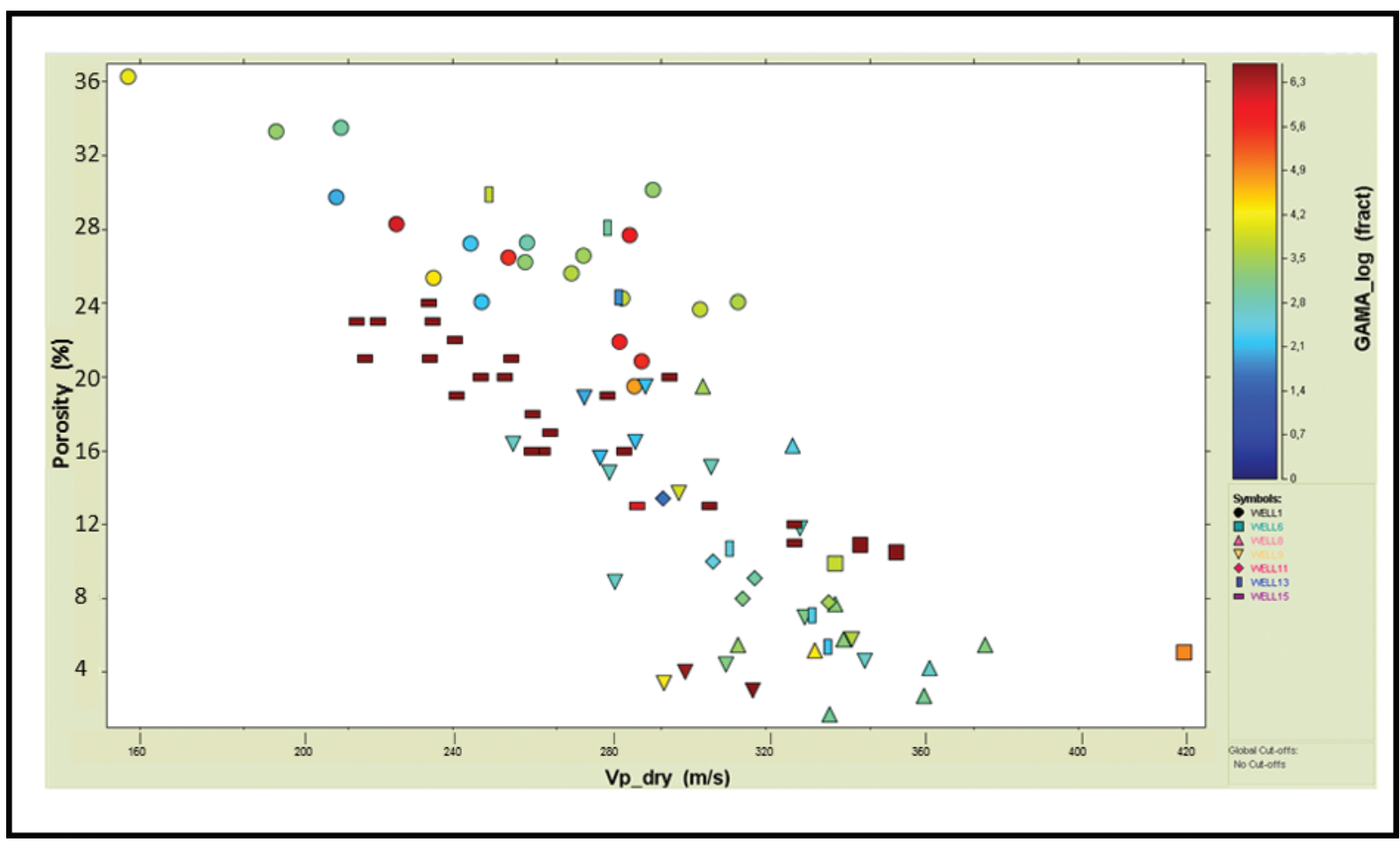

Figure 6 - Diagram porosity versus dry P-velocity ${ }^{\star}$, colored according to gamma values that ranged between 1.5 and 6 . It is a parameter very sensitive to pore tortuosity and complexity, but alone is not an efficient separator of carbonate rocks/pore types. *A splitter was used on P-velocity.

types. However, analyzing the wells individually for the same porosity, the rocks with higher microporosity had lower velocities and gamma values (Fig. 6).

AR defines pore flattening and it is a good parameter to identify elongated pores. The higher the $\mathbf{A R}$ is, the more elongated is the pore. AR varied between 0.2 and 1.0. The samples with high velocity values had the highest $\mathbf{A R}$, showing a trend towards higher speeds for elongated pores (Fig. 7).

DOM values ranged from less than $100 \mu \mathrm{m}^{2}$ to about $600 \mu \mathrm{m}^{2}$ (Fig. 8). However, for the majority of the samples analyzed, DOM values were up to $150 \mu \mathrm{m}^{2}$. The diagram of Figure 8 shows that for a given porosity, the highest values of velocity had also the highest DOM values, in general. High DOM values indicate the presence of large pores in the thin section as observed in Figure 10, where a sample with vuggy porosity displays DOM $520 \mu \mathrm{m}^{2}$.

The PoA values varied between 10 and $520 \mathrm{~mm}^{-1}$ (Fig. 9) and, generally, lower $\mathbf{P o A}$ indicates simpler pore geometry and/or larger pores. As an example, for a given porosity, $30 \%$ of the samples with low PoA value have, relatively, higher velocity than the samples with high PoA (Fig. 9). Therefore, the simple geometry and/or large pores are faster than small and/or complex structure pores. Figure 10 shows the low PoA value, $50 \mathrm{~mm}^{-1}$, for a thin section of a sample with vuggy porosity and large pores.

In summary, each particular parameter describes best the following: Gamma, the aspects of pore tortuosity; DOM, the dominant pore size; PoA, perimeter of the area, sensitive to the tortuosity of pore shape and size; $\mathbf{A R}$, axis ratio, distinguished well compressed pore spaces, but ineffective to recognize complex shapes or small pores. In general, grainstones with large pores had high DOM and low PoA. On the other hand, packstones, wackestones and mudstones with high microporosity had high PoA and low DOM. Figure 10 shows a summary of these results, the PoA vs. DOM plot for all thin sections analyzed and a few images of the sections indicating the respective $\mathbf{P o A}$ and $\mathbf{D O M}$ parameters.

The mapping of pore type obtained in this study is in agreement with the results reported by other authors (Baechle et al., 2004; Weger, 2006); therefore, it was possible to determine pore geometrical features using the thin sections. The robustness of the results encourage the use of these pore parameters to reduce the dispersion observed in the relationship between P-wave velocities and the respective porosity determined for plugs of rocks (Daltro de Castro \& Rocha, 2011).

It can be clearly seen that the individual use of these parameters did not allow defining the specific pore type for the situations where the same porosity had different velocity values. The 


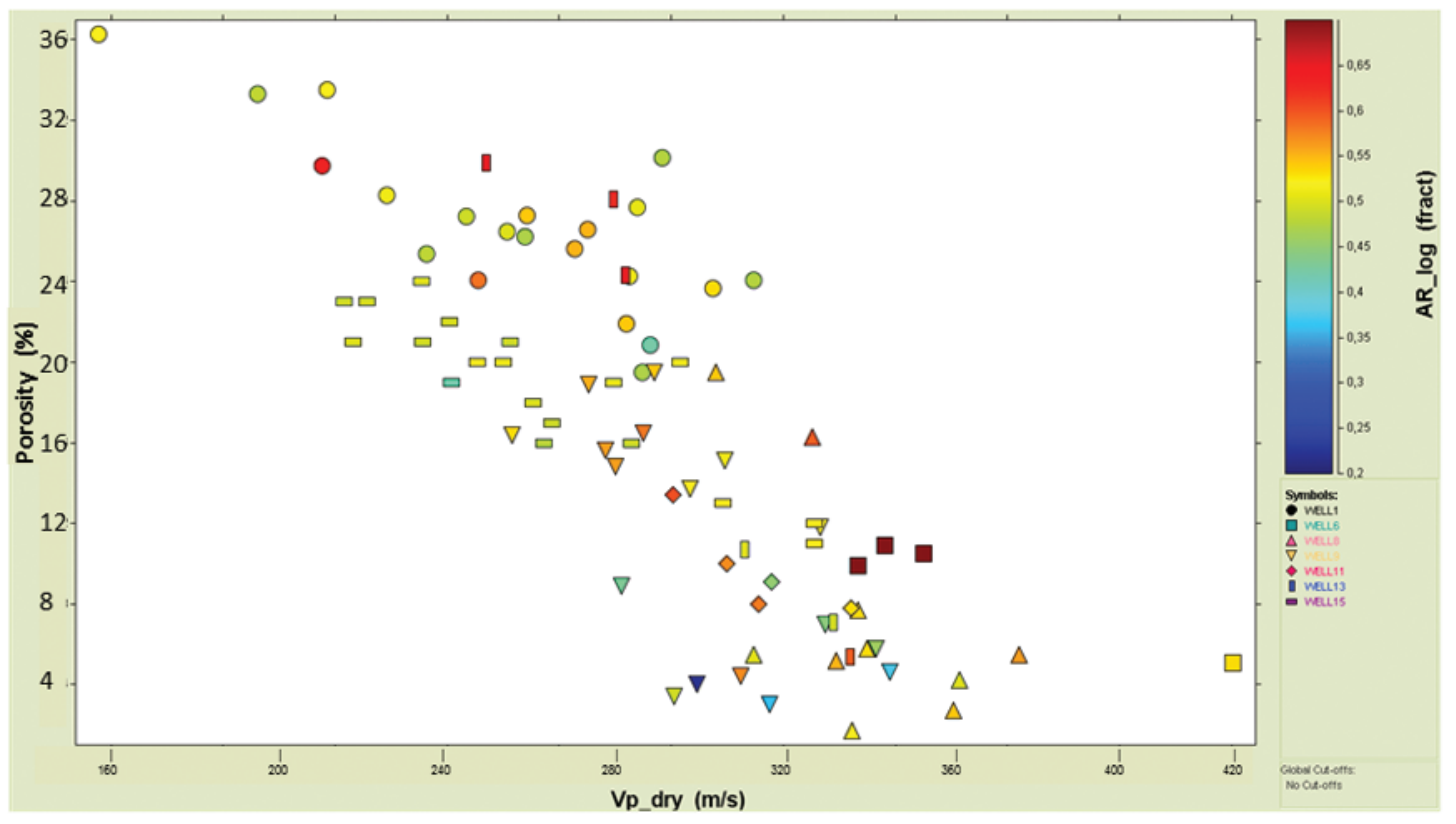

Figure 7 - Diagram porosity versus dry P-velocity*, colored according to AR values that ranged from 0.2 to 1.0. Samples with high velocity values have high AR, showing a trend towards high velocities for elongated pores. *A splitter was used on P-velocity.

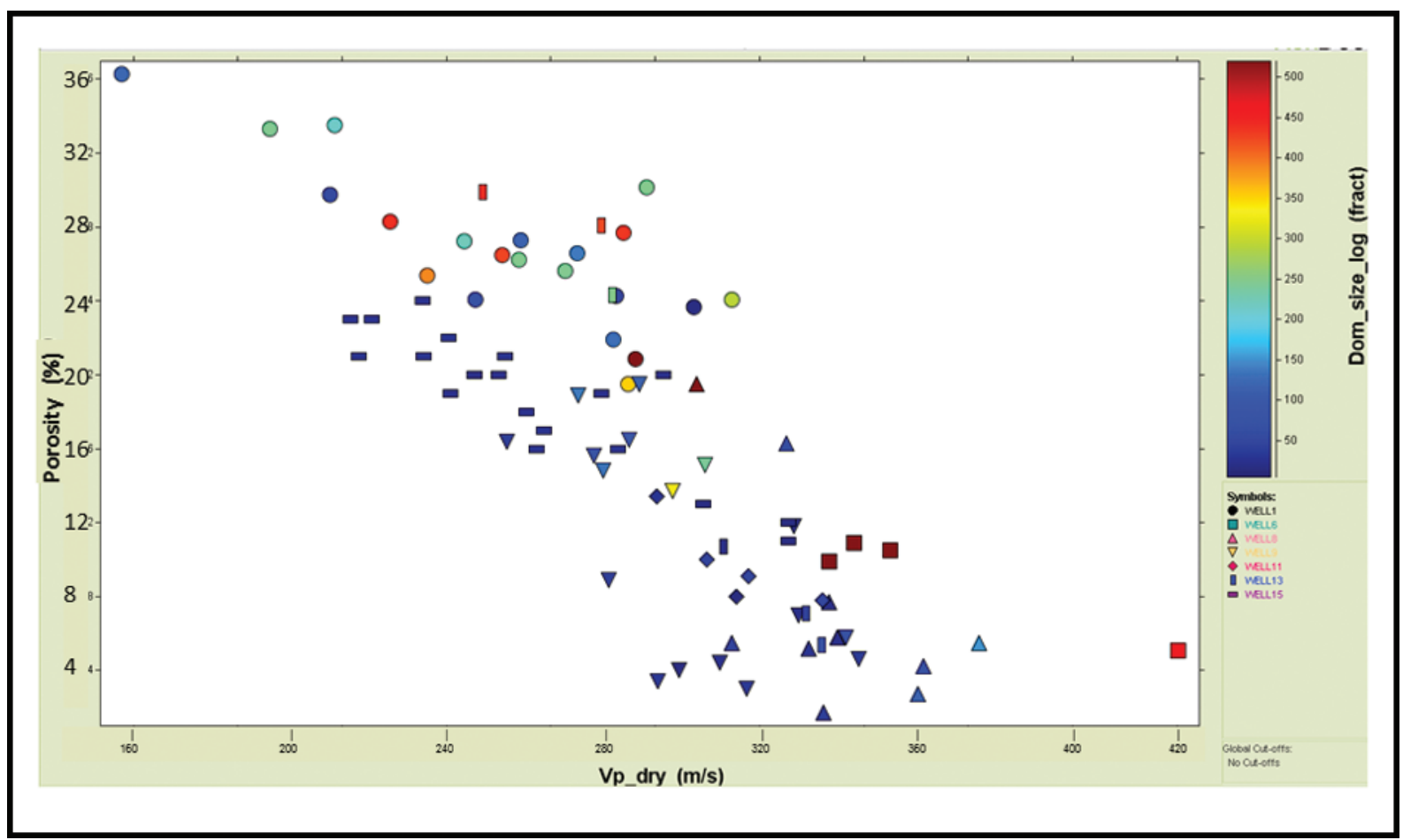

Figure 8 - Diagram porosity versus dry P-velocity*, colored according to DOM values that ranged from $100 \mu \mathrm{m}^{2}$ to about $600 \mu \mathrm{m}^{2}$. In general, to a given porosity, higher velocity values have also higher DOM. High DOM values indicated the presence of large pores in the thin section. *A splitter was used on P-velocity. 


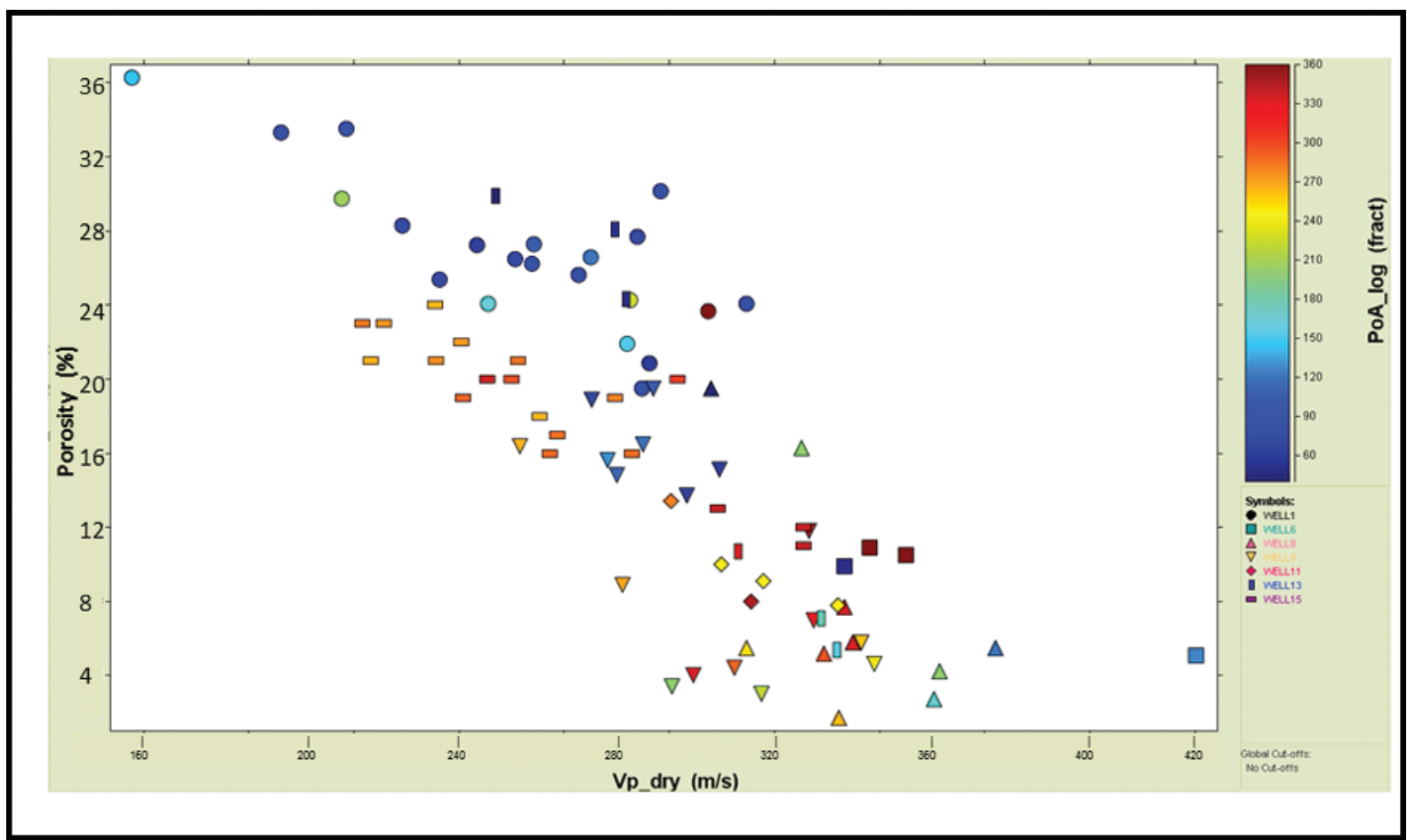

Figure 9 - Diagram porosity versus dry P-velocity ${ }^{\star}$, colored according to PoA values that ranged from 10 to $520 \mathrm{~mm}^{-1}$. In general, low PoA values indicate simpler pore geometry and/or larger pores. At a given porosity, $30 \%$ of the samples with low PoA have, relatively, higher velocities than samples with high PoA. *A splitter was used on P-velocity.

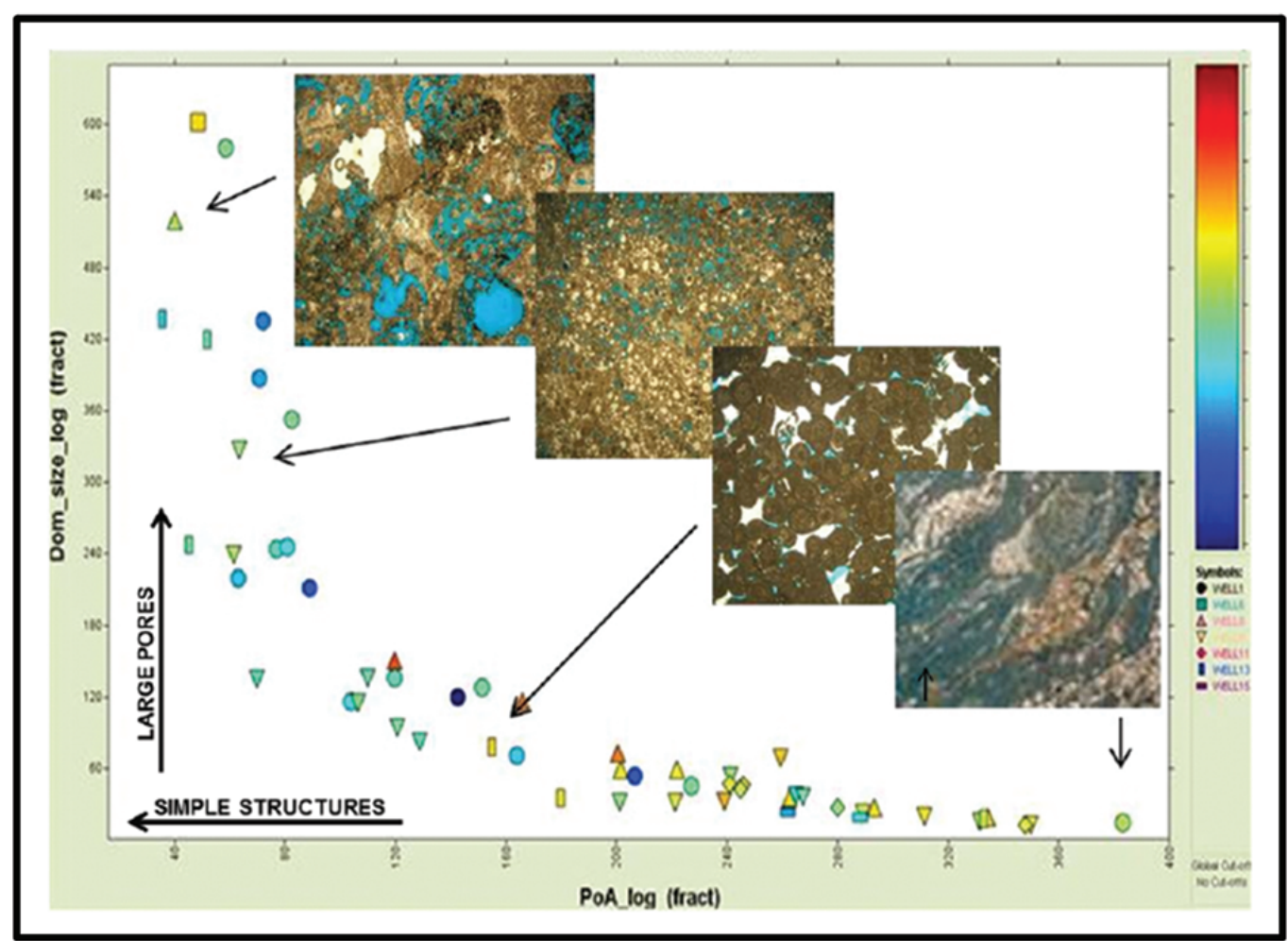

Figure 10 - Diagram PoA (perimeter over area) versus DOM (dominant size) of all thin sections analyzed. The images show thin sections that illustrate types of carbonate rocks and pore types. Simple pore structures whose round shape is close to the circle, have low PoA values while large pores have high DOM. 
direct correlation of each parameter with porosity did not reduce effectively the ambiguities identified in the porosity and velocity correlations. As the direct use of the information was not efficient, an attempt was made to apply another methodology to incorporate pore geometry. Two methodologies for correlations between the pore geometric parameters and porosity were analyzed: multivariate linear regression and canonical correlations analyzes. In the first, the only dependent variable is defined as a linear function of a set of independent variables while in the second, sets of dependent and independent variables are interrelated. In this study, the multiple linear regression analysis was considered more suitable because it predicts the value of a single dependent variable, velocity, from a linear function with a set of independent variables that uses all four studied parameters (Gamma, DOM, PoA and $\mathbf{A R}$ ).

After determining the linear relationship between velocity and porosity, $R^{2}$ value 0.665 , the multivariate linear regression was performed combining each geometric parameter PoA, DOM,

Gamma and $\mathbf{A R}$ with porosity values, defining mathematical expressions for the correlations. Subsequently, the geometrical parameters were added two by two to the porosity values until all the parameters were included.

The correlation coefficients $\left(R^{2}\right)$ of P-wave velocity with porosity for multivariate analysis with the geometrical parameters Gamma, AR, PoA and DOM were 0.667, 0.688, 0.695 and 0.727 , respectively (Table 1 ). It is observed that Gamma was the least important in the correlation and $\mathbf{D O M}$, followed by PoA, increased the most the correlation between porosity and acoustic velocity. DOM is the dominant pore size of the sample and PoA defines pore size and its complexity. Summarizing, at a given porosity and high velocities DOM is high and PoA low; and for low velocities, DOM is low and PoA high. It can be stated that both parameters affect significantly the dispersion observed in the linear correlation diagram, velocity vs. porosity. Even considering the greater weight of these two on the correlations, we performed a linear combination of all the geometric parameters and the porosity that yielded the correlation $\mathrm{R}^{2}$ 0.883 (Table 1), and the correlation equation was used to estimate the velocities of the compressional waves of the carbonate rock samples studied (Fig. 11).

When pore geometry was taken into account for the studied carbonate rocks, the observed 30\% increase in the velocity and porosity correlation, changing from $0.66 \%$ to $0.88 \%$ (Fig. 11), shows the importance of geometry in these relationships. Figure 11 shows the dispersion values of velocity that decreased from $80 \mathrm{~m} / \mathrm{s}$ to less than $30 \mathrm{~m} / \mathrm{s}$.
Table 1 - Correlation coefficients $\left(R^{2}\right)$ of thirteen multivariate linear regressions using independent variables to define the acoustic velocity dependent variable. The combination of some parameters with porosity did not provide large increases in correlation coefficients. The use of the four pore geometric parameters DOM, PoA, AR and Gamma provided the best correlation value.

\begin{tabular}{|c|c|}
\hline Estimators used for & $R^{2}-$ V \\
\hline P wave velocity prediction & 0.666 \\
\hline Porosity & 0.667 \\
Porosity \& $\gamma$ & 0.688 \\
Porosity \& AR & 0.69 \\
Porosity \& $\gamma$ \& AR & 0.695 \\
Porosity \& POA & 0.697 \\
Porosity \& POA \& $\gamma$ & 0.709 \\
Porosity \& POA \& AR & 0.727 \\
Porosity \& DOM & 0.727 \\
Porosity \& PoA \& DOM & 0.751 \\
Porosity \& $\gamma$ \& DOM & 0.797 \\
Porosity \& AR \& DOM & 0.85 \\
Porosity \& PoA \& DOM \& AR & 0.883 \\
Porosity \& PoA \& DOM \& AR \& $\gamma$ &
\end{tabular}

Figure 11 also shows the acoustic velocity values defined by the Wyllie equation. This equation has been used for many years to calculate porosity from the acoustic velocity and was defined for water-saturated rocks, where the velocity of both the matrix rock and fluid are fixed and the only variable is porosity. Besides the fact that this equation was defined for siliciclastic rocks, parameters such as mineralogy, cementation, compaction and pore geometry are not taken into account. Even though, some authors (Anselmetti et al., 1998; Anselmetti \& Eberli, 1999) applied this equation to carbonate rocks and reported that rocks with microporosity and intergranular porosity deviated little from the velocities calculated by the Wyllie equation while moldic carbonate rocks, vuggy and with intergranular porosity, deviated considerably from the values given by the equation. In this study, only samples of rocks with low intergranular porosity and microporosity approached the values given by the Wyllie equation.

\section{CONCLUSIONS}

The use of digital image analysis of thin section allowed the definition and separation of pore space of the studied carbonate rocks, especially when the XPL ( $x$-polarized plane light) images were used.

The geometric parameters that varied the most and were better able to quantify the differences in pore shapes of the studied thin sections were as follows: DOM, PoA, Gamma and $\mathbf{A R}$, which are pore dominant size, pore size and complexity, and pore 


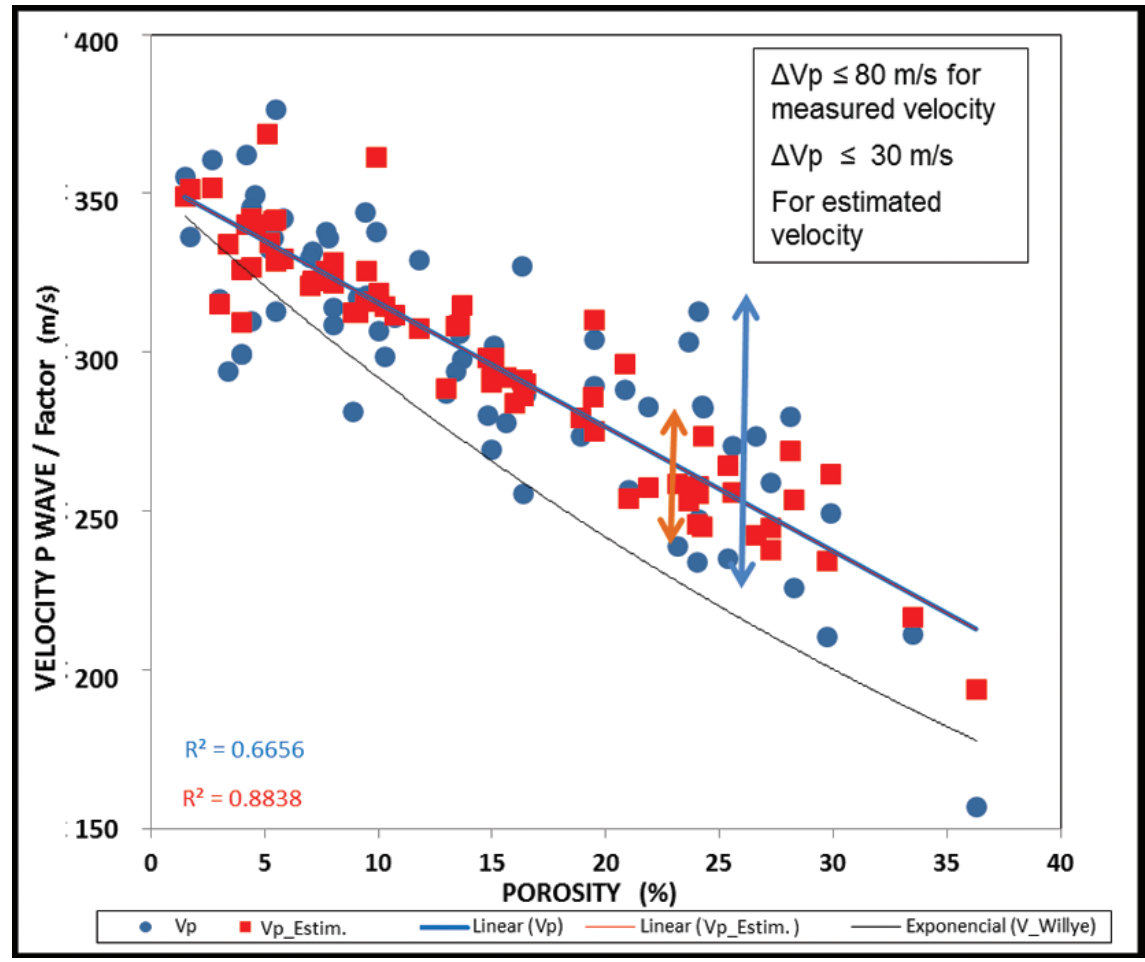

Figure 11 - Diagram porosity versus dry P-velocity ${ }^{*}$, the measured velocities colored in blue and the velocities estimated from the pore shape and type parameters in red. "A splitter was used on P-velocity.

tortuosity and roundness, respectively. From these parameters, DOM and PoA are the most important since, for a given porosity they separate fast rocks (high velocity) from slow rocks (low velocity). Since both parameters are associated with pore size, it was observed that the acoustic velocity is sensitive to pore size. The high linear correlation among acoustic velocity, porosity and the four geometric parameters enabled to define an empirical equation to express acoustic velocity as a function of porosity and pore geometry parameters. The parameters capture the peculiarities of pore shapes and improve the linear correlations between porosity and P-wave velocity of the analyzed data by $30 \%$.

The good correlations found, using pore geometric parameters, between acoustic velocity and porosity are encouraging and suggest that they may also be applied to estimate permeability. Thus, DOM and PoA could be used to identify high and low permeability values at a given porosity.

\section{ACKNOWLEDGMENTS}

The authors are thankful to the professors of UFRJ, especially Leonardo Borghi and to the University of Miami (UM), especially Gregor Eberli, for their collaboration, discussions, criticisms and suggestions. Thanks are also due to Klaas Verwer and Ralf Weger for the training in the use of the petrophysical laboratory equipment of UM and collaboration, discussions, criticisms and suggestions.

\section{REFERENCES}

ANSELMETTI FS, LUTHI S \& EBERLI GP. 1998. Quantitative Characterization of Carbonate Pore Systems by Digital Image Analysis. AAPG Bulletin, 82(10): 1815-1836.

ANSELMETTI FS \& EBERLI GP. 1999. The velocity-deviation log: A tool to predict pore type and permeability trends in carbonate drill holes from sonic and porosity or density logs. AAPG Bulletin, 83(3): 450-466.

BAECHLE G, WEGER R, EBERLI G \& MASSAFERRO J. 2004. The role of macroporosity and microporosity in constraining uncertainties and relating velocity and permeability in carbonate rocks. In: $75^{\text {th }}$ SEG Intern. Annual Meeting, Denver. CD-ROM.

CHOQUETE PW \& PRAY LC. 1970. Geological Nomenclature and Classification of Porosity in Sedimentary Carbonates. AAPG Bulletin, 54(2): 207-250.

DALTRO DE CASTRO D \& ROCHA PF. 2011. Petrophysical Characterization of Carbonates. In: The 12th International Congress of the Brazilian Geophysical Society. Rio de Janeiro, Brazil, August 15-18, 2011. CDROM. 
DUNHAM RJ. 1962. Classification of Carbonate Rocks According to Depositional Texture. AAPG Bulletin, 54(2): 108-121.

EHRLICH R, CRABTREE SJ, KENNEDY SK \& CANNON RL. 1984. Petrographic image analysis I; analyses of reservoir pore complexes. Journal of Sedimentary Petrology, 54: 1365-1376.

EHRLICHR, ETRIS EL, BRUMFIELD D, YUAN LP \& CRABTREE SJ. 1991. Petrography and Reservoir Physics III: Physical Models for Permeability and Formation Factor. AAPG Bulletin, 75(10): 1579-1592.

GERARD RE, PHILIPSON CA, MANNI FM \& MARSHALL DM. 1992. Petrographic image analysis: an alternate method for determining petrophysical properties. In: PALAZ I \& SENGUPTA SK (Eds.). Automated pattern analysis in petroleum exploration. New York, Springer Verlag. 249-263.

HAN DE-HUA. 2004. Velocity in Carbonate Rocks. Fluids DHI, 1-13. University of Houston, Internal Publication.

LUCIA F. 1995. Petrophysical parameters estimated from visual descriptions of carbonate rocks: A field classification of carbonate pore space. J. Petr. Tech., 629-637.
McCREESH CA, EHRLICH R \& CRABTREE SJ. 1991. Petrography and reservoir physics II: relating thin section porosity to capillary pressure, the association between pore types and throat size. AAPG Bulletin, 75: 1563-1578.

RAFAVICH F, KENDALL CG St C \& TODD TP. 1984. he relationship between acoustic properties and the petrographic character of carbonate rocks. Geophysics, 49: 1622-1636.

RUSS JC. 1998. The image Processing Handbook: Boca Raton, FI., CRC Press, $771 \mathrm{pp}$.

SALEH AA \& CASTAGNA JP. 2004. Revisiting the Wyllie time average equation in the case of near-spherical pores. Geophysics, 69: 45-55.

VERNIK L \& NUR A. 1992. Petrophysical classification of siliciclastics for lithology and porosity prediction from seismic velocities. AAPG Bulletin, 76: 1295-1309.

WEGER RJ. 2006. Quantitative Pore/Rock Type Parameters in Carbonates and their Relationship to Velocity Deviations. Ph.D. Dissertation. University of Miami. 232 pp.

\section{NOTES ABOUT THE AUTHORS}

Dayse Daltro de Castro. Graduated with a BS in Geology from the Universidade do Estado do Rio de Janeiro (UERJ) and Master of Sciences in Marine Geology from the Universidade Federal do Rio de Janeiro (UFRJ). Currently, she is pursuing her PhD at Universidade Federal do Rio de Janeiro (UFRJ) in partnership with the Department of Geophysics and Marine Geology, University of Miami (FL, USA) in the field of rock physics and seismic attribute analysis. Since 1987, she works in the oil industry with specialization in geophysics for characterization and exploitation of oil reservoirs.

Paula Lucia Ferrucio da Rocha. Graduated in Physics and has a PhD in Potential Methods from the Universidade Federal do Rio de Janeiro (UFRJ). Professor of Geophysics at Universidade Federal do Rio de Janeiro since 1992, and since 2011 at Universidade Federal de Brasília at the Institute of Geosciences. 